\title{
Social Capital and the Equalizing Potential of the Internet
}

\author{
Hans Pruijt \\ Erasmus University Rotterdam, PO Box 1738, 3000 DR Rotterdam, The Netherlands \\ Pruijt@fsw.eur.nl
}

Preprint. Published in Social Science Computer Review, 2002, Vol. 20 No. 2, 109-115

\begin{abstract}
Social capital is predominantly seen as a public good. Internet communication tends to complement real-world interaction. Therefore, concerns that it might contribute to a decline of social capital seem unfounded. Internet communication can support and enhance communities that to some extent depend on face-to-face interaction. Taking the online communication of computer professionals as a model, the paper seeks to demonstrate the power of virtual communities. Examples are the development of Linux and users reactions to a bug in the Pentium processor. Online communication, facilitated by personal home pages and search engines, offers isolated workers opportunities for increasing their private good social capital as well.

On the level of infrastructure, key characteristics of the Internet match those of social capital: the network aspect itself, cooperation, voluntary work, giving, standards of social behavior and the fact it is not designed. Downsides of the Internet also correspond to downsides of social capital: exclusion, a trade-off between openness and trust and support for destructive forces. Realizing the equalizing potential of the Internet in terms of social capital requires action; there is also a possible scenario in which social capital is undermined.
\end{abstract}

Keywords: Internet, Social Capital, Computer Mediated Communication, Social Theory

The title of this article may seem contradictory because the Internet can be seen as one more source of inequality. Undeniably there is a digital divide between wealthy and poor, between well educated and less educated, and between the developed and the underdeveloped world. Nevertheless, the Internet has an equalizing potential as well, especially in terms of social capital. In terms of economic capital, the Internet tends to facilitate monopolization. (Bar, Richards et al., 2000).

Like any other popular concept in social science, social capital does not have one precise universally shared meaning. However, the most common view is that social capital is a public 
good. In this approach the central proposition is: if someone makes an investment in social capital in a particular social group, it is not he or she who primarily reaps the benefits; such an investment benefits all group members (Coleman, 1990, pp. 315-318).

In order to sustain their society, its inhabitants must be able to overcome the dilemmas of collective action -- cooperating at the risk of being exploited versus muddling through alone at impossible tasks that would be light work when tackled collectively. The capability to overcome these dilemmas is social capital. Associations and networks, particularly voluntary and horizontally organized, and trust as a social lubricant, are its prime components. Like economic capital, social capital can be built up over time. In the late 1990's, partly as a result of provocative writings by Robert Putnam (1993a, 1993b, 1995, 1996), it has been adopted in the US across a wide political spectrum as a panacea for all that seems dysfunctional in society: failing education, industrial decay, crime, racial tensions etc.

Nations or regions can be unequal in terms of social capital. Fukuyama (1995) ranked the US, Germany and Japan on the basis of indicators of social capital. Putnam (1993a) explained the relative misery of Southern Italy from its lack of social capital, as compared to the northern part.

\section{Internet use as a slice of the time budget}

In the US, Putnam $(1995,1996)$ found a long-term decline in social capital, measured as participation in voluntary associations. Putnam (1996) singled out TV watching as the prime destroyer of social capital. He suggested that increased Internet use did not constitute a reversal of the decline of social capital, because meeting electronically is not equivalent to meeting face-to-face (Putnam, 1995, p. 76). If, however, Internet use comes at the expense of TV watching there is no reason to believe that it contributes to a decline of social capital 
(Pruijt 1997). Indeed, a UK survey showed that Internet use tends to come at the expense of TV watching rather than of maintaining real-world contacts (Gardner and Oswald, 2001). And in an US survey 39 per cent of respondents reported that their Internet use decreased the amount of time that they spent watching TV (Nie and Erbring, 2000). Wellman, Quan Haase et al. (2001) found that e-mail tends to be used as a supplement to face-to-face and telephone communication, rather than as a replacement.

\section{Online support for offline communities}

It seems uncontested that online support is valuable for communities that are to some extent based on face-to-face interaction. Zuboff (1988, pp. 362-386), for example, described how workers in a drug company used a computer conference system. She concluded that "knowledge displayed itself as a collective resource; non-hierarchical bonds were strengthened; individuals were augmented by their participation in group life; work and play, productivity and learning, seemed ever more inseparable.” (Zuboff, 1988, p. 386). Pliskin (et al., 1997) showed how e-mail was used by Israeli academic staff members on strike to enhance cohesion. Lee (1997) gives scores of examples of Internet use by unions around the world, such as on-line strike newspapers, on-line discussion groups for members and interunion communication (see Taylor, 1996). Many, e.g. Schuler (1996) have shown how "Free"Nets" or "Digital Cities" can be used for strengthening local communities. Electronic communication researchers Sproull and Kiesler (1991, p. 90) reported: "Respondents seem to believe that sharing information enhances the overall electronic community and leads to a richer information environment. The result is a kind of electronic altruism quite different from the fears that networks would weaken the social fabric of organizations." 


\section{How virtual are virtual communities?}

There is reason to believe that electronic communication has serious limitations when compared to face-to-face communications. Nohria and Eccles (1992) concluded that network organizations need face-to- face communication for handling situations of uncertainty and ambiguity. Ellen Ullman noted that online communities tend to be affinity groups in which "real difference is shunned" (Mathieson, 1998). However, these limitations do not preclude that online communities may be seen as a boon to social capital. The World Bank (1999), for example, promotes online communities as a development strategy: "information technology has the potential to increase social capital - and in particular bridging social capital which connects actors to resources, relationships and information beyond their immediate environment. [..] the internet offers opportunities to enhance social capital among craftspeople within a cooperative and builds bridging social capital by connecting producers and consumers who would otherwise not be able to do business together. Examples of such NGOs include PEOPlink, Institute for Economic Justice and Indigenous Technology, and Aid to Artisans."

To observe social capital in online communities at work, it is convenient to start looking in an area where a lot has been accumulated already. Computer professionals were among the first categories of people who started using the Internet. Therefore, I will concentrate on the communication among computer professionals.

Usenet News carries a few thousand newsgroups on different subjects. Some of these newsgroups exhibit a more than passing resemblance to the inside of men's lavatory doors in schools. In the professional newsgroups however (for example: comp.databases.ms-access), substantive technical discussion takes place. Participants post technical queries, generally on day-to-day technical problems that could not be solved by asking coworkers. Answers tend to 
come quickly. Other postings raise debate. These debates consist of a string that may be twenty or thirty postings long. (Noise postings occur in all newsgroups. Anyone can post anything. All that serious users can do against noise postings is protest.)

- Newsgroups, web-based forums and discussion lists have many casual visitors. Nevertheless one also finds participants who seem to subscribe to the motto "Ask not what your virtual community can do for you—ask what you can do for your virtual community". They answer questions nearly every day, or gather knowledge in FAQ's, or act as (in)formal moderators. It is because of the actions of such people that one can speak of social capital rather than just public places in cyberspace.

The debates in the newsgroups are not inconsequential. In 1994, a user discovered a bug in the Intel Pentium processor. This information was made public in the comp.sys.intel newsgroup, leading to a wide debate. Intel spokespeople tried to downplay the problem. However, mounting users' protests caused Intel to adopt a replacement policy costing \$ 475 million.

A strong demonstration of the potential power of on-line communities is the ongoing cooperative development of the Linux operating system. Programmer Linus Torvalds donated the basis to the Internet community in 1991. Since then, programmers around the world contributed bits and pieces (Helmers and Seidler, 1994). On the Intel platform, the resulting free - product emerged as the major alternative to Microsoft's offerings.

There is no reason why this level of Internet communication and community building should be restricted to computer professionals. Workers in all trades can benefit by connecting to their peers in other organizations (and in their own organization as well).

\section{Private good social capital and Internet use}


So far, I have focused on the public good perspective on social capital. There also is a private good perspective (INSNA, 1997). This perspective focuses on how people make use of their connections to further their interests. Bourdieu (1986) uses the label social capital for networks of advantageous contacts. These are created and maintained at the individual level but also at the aggregated group or family level.

From studies on elites (for example Helmers et al., 1975, Burt, 1997), we know that the top people are usually "well connected", they know the right people in other organizations. Workers who are lower down in the hierarchy tend to lack those connections.

Isolated workers struggling with some problem can use the Internet search engines, like Google, to find people anywhere who would be likely to be dealing with the same problem in order to share their experiences. More and more, users are creating personal homepages on which they state their professional and other interests. In this way, they increase the chances for getting in touch with people who share their interests. Participation in communities, such as Usenet Newsgroups, can lead to contacts as well. The new contacts can support workers who want to preserve their professional identity in the face of divide-and-conquer organizational politics. Resulting ties tend to be weak and handy; sometimes they develop into strong ties (Wellman, 1997).

\section{The Internet is social capital}

The Internet phenomenon has been hard to pin down. Various metaphors have been tried, such as the information highway, the digital library or the electronic marketplace (Stefik, 1996.) Such metaphors do not capture the Internet's dynamics. Defining the Internet as a technological innovation, as does, for example, Graham (1999), may be slightly misleading as well. Computer networking is certainly a technology. The Internet, however, is a network 
of networks. The basis is a set of protocols or standards (TCP/IP): agreements on how to structure packets of data, and on how to route these packets from node to node around the world. This involves a global addressing scheme. The Internet standards allow users to send information to any computer on the net, to open up computers for delivery of information and to accept commands given from remote computers.

The Internet does not own anything. Neither is the Internet owned by anyone. There is no membership; it is not an organization. The characteristics of the Internet very closely match the structure of social capital:

- Networks are central in social capital.

- Cooperation: the Internet is run cooperatively by various government agencies, member networks, private carriers and The Internet Society, a non-profit professional association.

- Voluntary work: one of the key bodies of the Internet Society is the Internet Engineering Task Force, a voluntary group that coordinates technical matters. The standards evolve constantly, through what is known as RFC's, requests for comments (see Hoffmann, 1995). This evolution leads to steadily extended functionality. A second Internet Organization worth mentioning in the context of social capital is the Electronic Frontier Foundation, which was founded to "help civilize the electronic frontier; to make it truly useful and beneficial to everyone, not just an elite; and to do this in a way that is in keeping with our society's highest traditions of the free and open flow of information and communication" (in: LaQuey, 1993, p. 126).

- Giving is essential in social capital. It is also a vital element in Internet culture. The necessary software components tend to be contributed free or as shareware. Various 
information sources are provided free of charge. (This refers to giving in the altruistic sense. Giving can also be part of a business model based on getting people hooked.)

- Apart from standards for technical behavior, there are standards for social behavior, the "Netiquette", which are explained in beginner's books (see LaQuey, 1993, pp. 69-73). These standards evolve to accommodate new phenomena, such as autonomous software agents (Helmers, Hoffmann and Stamos-Kaschke, 1997).

- The current Internet was envisioned by a few people, but never designed or planned (Rheingold, 1994).

At this point, the conclusion seems hard to escape that the Internet is social capital -- the emergent information society spawned its own social capital. Not only do the defining characteristics of social capital apply to the Internet, the downsides of social capital apply to the Internet as well. Portes and Landolt (1996) warn against seeing social capital as an unmixed blessing. One of their points is that networks can serve as mechanisms for social exclusion. One can recognize this point in the worries over the digital divide.

A second problem inherent in public good social capital is the trade-off between trust and openness. Trust helps keeping transaction costs small. A famous example of this role of trust is that of Jewish diamond traders in New York City who save lawyer's fees by trading informally (Coleman, 1990, p. 109). This level of trust is possible because it is a closely-knit community. The ARPANET, the predecessor to the Internet, was "a small community, and users left their doors unlocked, just as trusting folks in small towns do." (LaQuey 1993). Internet security problems are the result of the tension between openness (introduced when the Internet opened up to embrace basically anybody) and trust. Thus the success of the Internet architects, activists and administrators in overcoming exclusiveness has unintentionally paved the way for unwanted users. 
In normative discourse, there is a tension between, on the one hand, the notion that social capital is beneficial for society and, on the other hand, the realization that destructive forces such as criminal or terrorist organizations and neo-nazi groups also involve social capital. In this respect, the Internet is no exception. Since illegal organizations, because of their illegality, already conform to the image of the virtual organization, they do not need to go though an adaptation process when moving to the Internet.

\section{Discussion}

Social capital is the spirit of the Internet and also the direction in which its equalizing potentials can be found. It results in an internal drive to chip away at the digital divide. This is an explanation for the Internet's unprecedented worldwide growth rate. Getting connected means getting access to a stock of social capital. The value of this stock multiplies (exponentially) with the number of participants. At the same time, the ethical formula of the Internet requires participating organizations to help other organizations connect.

However, continuing investment in Internet social capital at all levels is needed. The flexibility of information technology is such, that the Internet infrastructure can just as easily be used for deploying applications that undermine social capital. For example, "allways on" Internet connections permit monitoring of home workers; permanent wireless Internet offers opportunities for surveillance and control.

A few practical implications are:

- In order to take advantage of the opportunities for overcoming worker isolation, internet use in education should not be restricted to information retrieval. Students at all levels should be encouraged to use the Internet for connecting to other people. They should also be able to make their own presence on the Internet. For instance, this means personal 
home pages for students and assignments that require students to locate fellow-students in other schools to cooperate with.

- For users who put information on the web it is important to make sure that search engines can find it. For this reason, online services that store information in databases rather than in HTML are to be avoided. (Information entered in Usenet News is also retrievable through a search engine, currently Google.)

- If the medium is the message, it is "many-to-many". Planners of future network infrastructures tend to ignore this at their peril (Perry, 1995, Weingarten and Overbey, 1995).

Acknowledgements: this paper benefited from comments made by Mart-Jan de Jong, Wim Blauw, Jan-Willem Scherrenburg and Inge Strubbe on an earlier paper.

\section{References}

Bar, F., J. E. Richards and C. Sandvig. (2000). The Jeffersonian Syndrome. The Predictable Misperception of the Internet's Boon to Commerce, Politics, and Community. Stanford, Department of Communication, Stanford University.

Bourdieu, Pierre (1986), "The forms of capital" in John G. Richardson (ed.) Handbook of theory and research for the sociology of education, New York: Greenwood Press

Burt, R. S. (1997). “The contingent value of social capital.” Administrative Science Quarterly 42(2): 339-365.

Coleman, J. S. (1990). Foundations of Social Theory. Cambridge, MA, Harvard University Press. 
Fukuyama, F. (1995), Trust. The social virtues and the creation of prosperity, London: Hamish Hamilton.

Gardner, J. and A. Oswald (2001). "Internet use: the digital divide" in. A. Park, J. Curtice, K. Thomson, L. Jarvis, C. Bromley and N. Stratford.et al (eds) British Social Attitudes. Public Policy, Social Ties.. Thousand Oaks, Sage. 18: 159-173.

Graham, G. (1999). The Internet. A Philosophical Inquiy. London, Routledge. INSNA (1997). Social Capital [archived SOCNET discussion], International Network for Social Network Analysis (INSNA). 2001. Available from the International Network for Social Network Analysis Web site: http://www.heinz.cmu.edu/project/INSNA

Helmers, S., U. Hoffmann and J. Stamos-Kaschke, 1997, (How) Can Software Agents Become Good Net Citizens?, Wissenschaftszentrum Berlin für Sozialforschung, http://duplox.wz-berlin.de/docs/cmc1/\#toc3

Helmers, H. M., R. J. Mokken, R. C. Plijter and F. N. Stokman (1975), Graven naar macht. Op zoek naar de kern van de Nederlandse economie, Amsterdam: Van Gennep. [Digging for power. Searching for the core of the Dutch economy.]

Helmers, S. and K. Seidler (1994), Linux: cooperative software development and Internet, Social Science Research Center Berlin, http://duplox.wz-berlin.de/docs/linux/amsterdam.html Hoffmann, U. (1995) "Request for Comments": Das Internet und seine Gemeinde, Social Science Research Center Berlin, http://duplox.wz-berlin.de/docs/jb/

LaQuey, T. (1993). The Internet Companion. A Beginner's Guide to Global Networking. Reading, Addisson-Wesley.

Lee, E. (1997), The labour movement and the Internet. The new internationalism, London: Pluto Press. 
Mathieson, R. (1998). “'Close' Call for a Technophile. The Ellen Ulman Interview." E.Business. www.hp.com/ebusiness/ullman.htm

Nie, N. and L. Erbring (2000). Internet and Society. A preliminary report. Stanford, Stanford Institute for the Quantitative Study of Society.

Nohria, N. and R. G. Eccles (1992). "Face-to-face: Making Network Organizations Work." in N. Nohria and R. G. Eccles (eds) Networks and Organizations. Boston, Harvard Business School Press: 288-308.

Perry, J. (1995). "Death from above.” Communications of the ACM 38(5): 17-21.

Pliskin, N., C. T. Romm and R. Markey. (1997). "E-mail as a weapon in an industrial dispute." New technology, work and employment 12(1): 3-12.

Portes, A. and P. Landolt (1996), "The downside of social capital," in: The American prospect no. 26 (May-June): 18-21, 94 (http://epn.org/prospect/26/26-cnt2).

Pruijt, H. (1997). "Social Capital, Computerization and the Internet: Implications for Work and Education." in M.-J. d. Jong and A. Zijderveld (eds) The Gift of Society. Nijkerk, Enzo Press: 63-73.

Putnam, R. D. (1993a), Making democracy work. Civic traditions in modern Italy, Princeton: Princeton University Press.

Putnam, R. D. (1993b), "The prosperous community: social capital and public life" in: The American Prospect no. 13, Spring ( http://epn.org/prospect/13/13putn.html).

Putnam, R. D. (1995), "Bowling alone: America's declining social capital”, in: Journal of democracy 6:1, Jan., 65-78.

Putnam, R. D. (1996), "The strange disappearance of civic America" in: The American Prospect, no. 24 (Winter 1996) [http://epn.org/prospect/24/24putn.html]. 
Rheingold, H. (1994), The virtual community. Finding connection in a computerized world, London: Mandarin, http://www.well.com/user/hlr/vcbook/index.html

Schuler, D. (1996), New community networks. wired for change, Reading, MA: Addison Wesley.

Sproull, L. and S. Kiesler (1991), “Computers, networks and work”, in: Scientific American, Vol 265 No. 3 September, 84-91.

Stefik, M. (ed) (1996) Internet dreams: archetypes, myths, and metaphors, Cambridge, MA.: MIT Press.

Taylor, Robert (1996), "United across the Internet: Robert Taylor explains why trade unions are planning greater international co-operation”, Financial Times, June 25, 16.

Wellman, B. (1997). "The Road to Utopia and Dystopia on the Information Highway." Contemporary Sociology 26(4): 445-449.

Wellman, B., A. Quan Haase, J. Witte and. K. Hampton (2001). Does the Internet Increase, Decrease, or Supplement Social Capital? Social Networks, Participation, and Community Commitment. Social Capital and Information Technology, World Bank, http://www.worldbank.org/poverty/scapital/topic/info1.htm.

Weingarten, F. and P. Overbey (1995), Culture, society and advanced information technology, Arlington and Washington: American Anthropological Association and Computing Research Association.

Zuboff, S. (1988), In the age of the smart machine. The future of work and power. New York: Basic Books. 